\title{
Field monitoring and model predicted water balance of monolithic cover
}

\author{
Md Jobair Bin Alam ${ }^{1, *}$, Asif Ahmed ${ }^{2}$, Md Aminul Islam $^{3}$, Naima Rahman ${ }^{4}$, and Md Sahadat Hossain ${ }^{5}$ \\ ${ }^{1}$ Prairie View A\&M University, Civil Engineering Department, 100 University Drive, Prairie View, TX 77446, USA \\ ${ }^{2}$ SUNY Polytechnic Institute, College of Engineering, 100 Seymour Road, Utica, NY 13502, USA \\ ${ }^{3}$ University of Texas at Arlington, Civil Engineering Department, 416 Yates Street, Arlington, TX 76019, USA \\ ${ }^{4}$ SCS Engineers, Department of Solid Waste Service, 12651 Briar Forest Drive, Houston, TX 77077, USA \\ ${ }^{5}$ University of Texas at Arlington, Civil Engineering Department, 416 Yates Street, Arlington, TX 76019, USA
}

\begin{abstract}
The use of the evapotranspiration cover for landfill is increasing because of its long-term enhanced performance. However, the performance of evapotranspiration cover primarily depends on the onsite geoclimatic conditions. Therefore, field verification of cover performance through constructed test plots is required before actual implementation. Additionally, numerical modeling and comparison with field results are necessary for future performance prediction. The objective of this study was to simulate the water balance hydrology of evapotranspiration cover using the code SEEP/W. Drainage lysimeter was constructed with finegrained soil and native vegetation. Field water balance data from the lysimeter were obtained through instrumentation. Onsite climatological data, laboratory and field investigated soil parameters and actual field studied plant parameters were used as model input. Based on one year's simulation, it was observed that the code nearly captured the seasonal variations in the water balance quantities measured in the field. Surface runoff was reasonably predicted in the model where precipitation intensity appeared to be responsible to some extent. Evapotranspiration was slightly overpredicted and the fluctuation in soil water storage was similar to the field results. The model predicted annual percolation was approximately $45 \mathrm{~mm}$, which is under-predicted than the actual field measured annual percolation of $62 \mathrm{~mm}$.
\end{abstract}

Keywords: Landfill, Water Balance Cover, Field Investigation, Numerical Modeling, SWCC

\section{Introduction}

Landfill owners and operators, now-a-days, are highly motivated to close their landfills with final covers which employ the water balance principles, because of its successful long-term performance. Water balance covers promote sustainability because of their low cost of construction with locally available materials, and function harmoniously with local hydrological processes. However, closure of municipal solid waste landfills is regulated through Resource Conservation Recovery Act (RCRA) in the United States. The RCRA and the U.S. Environmental Protection Agency (EPA) recommend using conventional covers, which employs a resistive barrier of compacted clay layers and geomembrane [1-4]. Nonetheless, RCRA ratifies the provision of water balance covers contingent upon satisfactory long-term field performance evaluated based on percolation rate.

Water balance covers, which is also known as evapotranspiration (ET) cover, control percolation by storing infiltrated water during precipitation periods in the cover soil pores by capillary action and release it to the atmosphere during the dry periods by evapotranspiration process [5-11]. Thus, water balance covers rely on the ability of fine-grained soils to retain water and the capability of the plants and atmosphere to remove water via transpiration and evaporation.

Design of water balance covers is mainly associated with investigating the hydraulic characteristics of the soil and thus identifying the required thickness of soil cover to store precipitation that infiltrates during the wet climatic events and evaluating whether the plants and the atmospheric condition can remove the stored water during the dry period. Hydraulic properties of the soil strongly influence the performance of water balance cover system. Additionally, the hydraulic properties of the soil, both saturated and unsaturated, are necessary for water balance modeling as input parameters. However, laboratory investigated soil hydraulic properties do not remain constant throughout its service life in the field and it varies seasonally due to the post-construction processes such as insect and animal burrowing, freeze-thaw cycling, wetdry cycling, and plant root growth and death [12-18]. These altered soil properties affect the percolation rate significantly.

The field performance of ET covers has been demonstrated in different regions of the United States [4, 19-21]. However, model verification has been evaluated in a very limited number of field studies [6, 22-24]. Additionally, model accuracy could not be established in

\footnotetext{
* Corresponding author: mdalam@pvamu.edu
} 
many of the verification because of limited dataset from the field studies. On top of that, in most of the model comparison, the critical vegetation parameters have not been measured due to complexities. Therefore, most model verification relied on available literature and calibration parameters for vegetation input.

In this paper, comparisons of field data from an instrumented test section (lysimeter) simulating a monolithic cover were made with numerical code, SEEP/W, which is developed specifically for evaluating the land-climate hydrology of covers. The lysimeter was constructed with local fine-grained soil at the City of Denton landfill. The soil and vegetation input to the model was based on the measurements using standard methods made in the laboratory and field, and the weather input was directly taken from the onsite weather station.

\section{Materials and Method}

\subsection{Test Section}

The field site is in Denton, TX, USA, which is approximately 40 miles northwest of Dallas. Denton is a semi-humid climatic region, with an average annual precipitation of $1000 \mathrm{~mm}$ and potential evapotranspiration to precipitation ratio $(\mathrm{PET} / \mathrm{P})$ of less than 1 to approximately 2 based on wet precipitation year. The average daily temperature ranges from $50^{\circ} \mathrm{F}$ in January to $90^{\circ} \mathrm{F}$ in August [25].

A large drainage lysimeter $(12.2 \mathrm{~m} \mathrm{x} 12.2 \mathrm{~m})$ was constructed in 2014 to evaluate the efficacy of the water balance cover. The lysimeter was constructed with local fine-grained soil which was classified as high plasticity clay $(\mathrm{CH})$ according to the Unified Soil Classification System [25]. The cover consists of $915 \mathrm{~mm}$ (3 ft.) of compacted clay, overlain by $305 \mathrm{~mm}$ (1 ft.) of a vegetated surface layer (Fig. 1). The lysimeter was lined with a geomembrane overlain by a geocomposite drainage layer. Percolation and surface runoff collection systems were installed consisting of HDPE pipes to capture these water balance components. After the construction of the lysimeter, extensive instrumentation was instated for continuous data monitoring. Data monitoring included soil moisture and temperature, soil suction, surface runoff, percolation, and climatic parameters. Soil water content was measured with 5TM soil moisture and temperature sensors in the cover as shown in Fig. 1. To monitor the soil suction, MPS-2 tensiometers were also installed alongside the moisture sensors (Fig. 1). The MPS-2 tensiometer tip is made of porous ceramic disc which measures the dielectric permittivity of the soil matrix to estimate its water potential. Measuring the dielectric permittivity of the disc allows wide range of moisture content measurements. The detailed description of the cover construction, profile, instrumentation, and vegetation properties can be found in [25].

The water balance of ET cover system consists of five components, which are: precipitation $(\mathrm{P})$, runoff $(\mathrm{R})$, evapotranspiration (ET), soil water storage (SWS), and percolation $\left(\mathrm{P}_{\mathrm{r}}\right)$. The SWS was computed by integrating the point measurement of water content from moisture sensors over the entire cover depth. Evapotranspiration was computed from the mass balance equation below:

$$
E T=P-R-P_{r}-\Delta S
$$

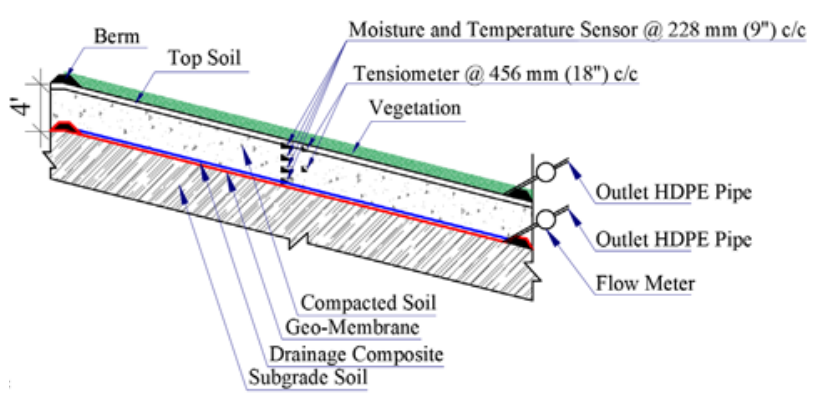

Fig. 1. ET cover Profile.

\subsection{Soil Characteristics}

Soil used during the construction of the lysimeter was collected from different layers and shipped to the laboratory for physical and hydraulic characterization. The physical characterization of the samples includes the particle size distribution (ASTM D 422), Atterberg limits (ASTM D 4318), compaction behavior (ASTM D 698). From the laboratory test results, the soil was classified as high plastic clay $(\mathrm{CH})$ based on the Unified Soil Classification System (USCS). The fine fraction (clay and silt) of the soil was approximately $88 \%$. Optimum moisture content (OMC) and maximum dry density (MDD) of the soil were approximately $17 \%$ and 17.4 $\mathrm{kN} / \mathrm{m}^{3}$, respectively.

\subsection{Hydraulic Properties}

Soil samples were collected from the test section during the construction stage. All samples were tested in the laboratory to determine the saturated hydraulic conductivity $\left(K_{S}\right)$ and the soil-water characteristic curve (SWCC) for drying. Flexible wall permeameters (ASTM D 5084) were used to measure $K_{s}$. SWCCs were measured as per ASTM D 6836 using a pressure cell apparatus and a chilled-mirror hygrometer (CMH). The $\mathrm{CMH}$ was used to determine the volumetric moisture content $(\theta)$ at higher suction $(\psi)$ levels, while the pressure cell device was used to determine the suction-moisture $(\psi-\theta)$ relationship at higher moisture contents. The van Genuchten's equation was fit to the experimental data and the van Genuchten curve fitting parameters are used herein to describe the SWCCs as shown in Fig. 2(a). The van Genuchten model [26] is a sigmoidal function. The equation of the sigmoidal function is represented as follow.

$$
\frac{\theta-\theta_{r}}{\theta_{s}-\theta_{r}}=\frac{1}{\left[1+(\alpha \psi)^{n}\right]^{m}}
$$

Where the $\psi$ parameter is the matric suction, $\alpha, n$, and $m$ are curve fitting parameters. The $\theta_{s}$ is the saturated volumetric water content, and $\theta_{r}$ is the residual volumetric water content. The unsaturated hydraulic conductivity function was developed using Fredlund and Xing model [27] as presented in Equation 3. The unsaturated hydraulic 
conductivity function is shown in Fig. 2(b). The saturated hydraulic conductivity of the calibrated model was $1.6 \mathrm{x}$ $10^{-6} \mathrm{~cm} / \mathrm{s}$ from the field investigation.

$$
K(\theta)=K_{s}\left[\int_{\theta_{r}}^{\theta} \frac{\theta-x}{\psi^{2}(x)} d x / \int_{\theta_{r}}^{\theta_{s}} \frac{\theta_{s}-x}{\psi^{2}(x)} d x\right]
$$

Where $K_{s}$ is the saturated hydraulic conductivity, $x$ is a dummy variable for integration, $\theta_{s}$ and $\theta_{r}$ are the saturated and residual volumetric water content, respectively.
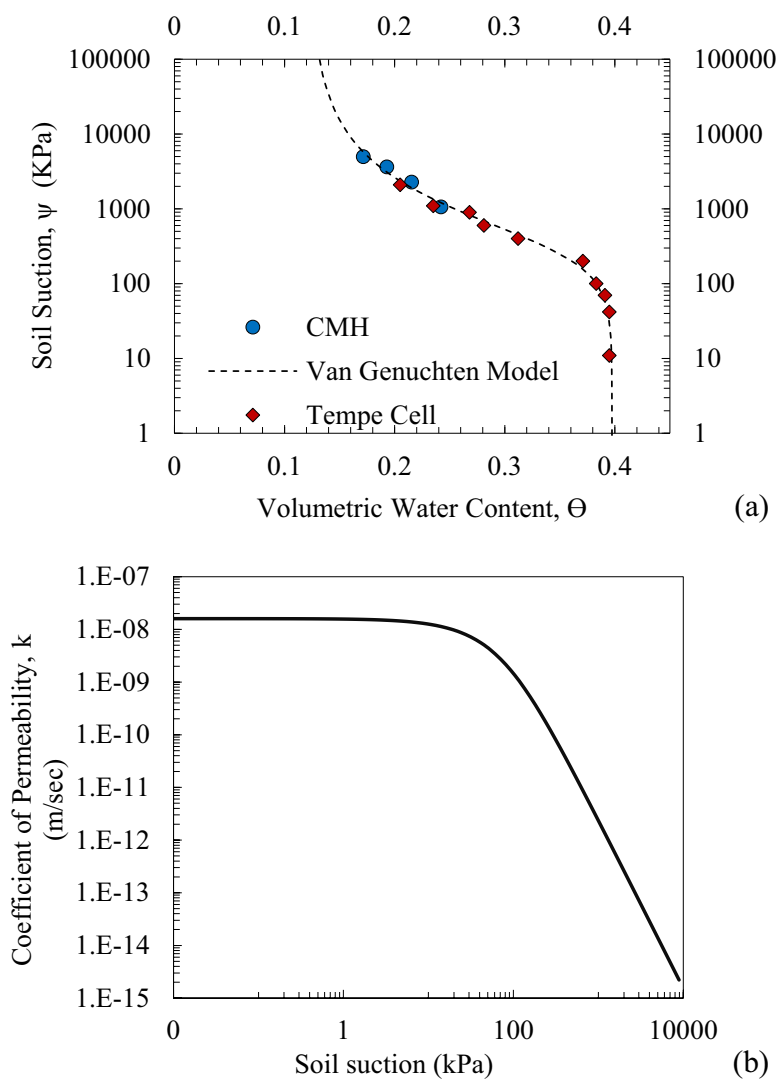

(b)

Fig. 2. Soil hydraulic properties: (a) Soil-water characteristic curve of cover soil and (b) Hydraulic conductivity function.

In addition to the hydraulic characterization of the soil in the laboratory, field testing was conducted to determine the in-situ $\mathrm{K}_{\mathrm{s}}$ using Guelph Permeameter (GP). The $\mathrm{K}_{\mathrm{s}}$ in the field increased as much as 400 times compared to laboratory-measured data during the monitoring period [12]. SWCCs representing in situ conditions were also constructed using the water contents and matric suctions measured in the field from the co-located sensors. van Genuchten parameters were fitted for the field generated SWCCs. The detailed procedures and the results of SWCC and saturated hydraulic conductivity are compiled in [12].

\subsection{Vegetation Properties}

Measurements of the roots (root distribution) were made four times a year in the lysimeter. Root depth measurements were made at the field using an installed acrylic tube. The roots extended approximately $356 \mathrm{~mm}$
(14") into the cover soil as can be seen from Fig. 3(a). It is also observed from the figure that it took almost 550 days for full root growth into the cover. A uniform leaf area index (LAI) was assumed based on available published data for Texas. Root length density (RLD) was measured in the laboratory on collected field specimens using the standard method. The RLD function is shown in Fig. 3(b). The RLD data were fitted with the exponential function suggested by Fayer [28].

$$
R=a \times e^{-b z}+c
$$

Where $\mathrm{a}, \mathrm{b}$, and $\mathrm{c}$ are fitting parameters, and $\mathrm{z}$ is depth. The fitting parameters used in the simulation were the average values of the last two measurements made in the year 2015, where $a=0.41, b=2.7$, and $c=0.0001$. Fig. 3(a) indicates that the rooting depth is approximately 356 $\mathrm{mm}$ (14") after almost 500 days after sowing. It was concluded by [25] that the root growth seized because of the existence of the compacted clay layer having bulk density over $1.6 \mathrm{~g} / \mathrm{cm}^{3}$. Ideal soil bulk density for efficient root growth is approximately 1.1 to $1.12 \mathrm{~g} / \mathrm{cm}^{3}$ according to USDA [29]. Based on the field observation, the root growth rate was approximately $1.65 \mathrm{~mm} /$ day.
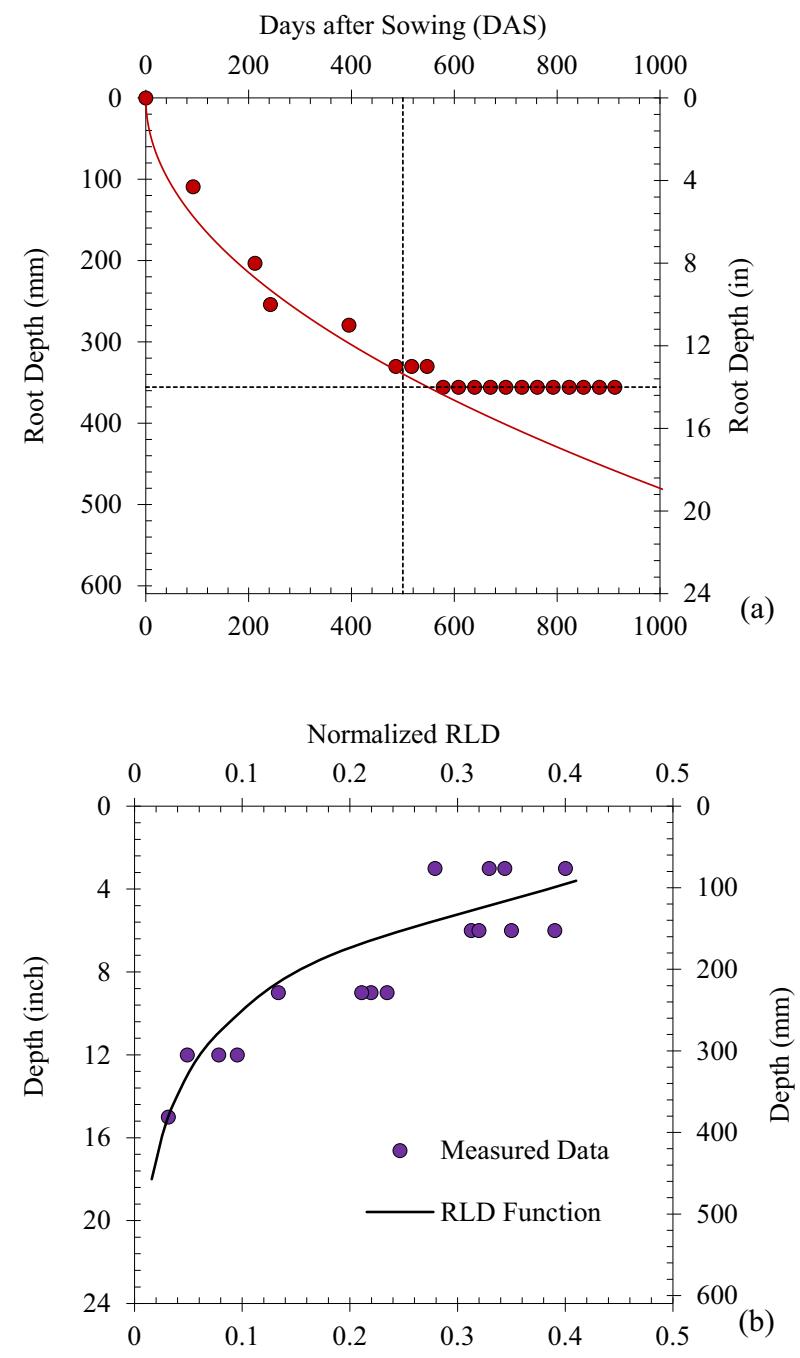

Fig. 3. (a) Rooting depth of vegetation (b) RLD function 


\subsection{Climatic Condition}

Data from the field-installed weather station were utilized in the seepage analyses of the cover soil. Fig. 4(a) shows the daily rainfall history of 2015 , applied in the study. Several heavy rainfall events with high precipitation intensity are observed from the figure. There were prolonged wet days from April to May, as well as from October to early November. During the summer, few rainfall events with high temperatures prevailed at the site. Fig. 4(b) depicts the temperature profile, along with the net radiation flux. As can be seen from the figure, the average temperature at the site during the summer was approximately $34^{\circ} \mathrm{C}\left(93.2^{\circ} \mathrm{F}\right)$. The temperature at the site was recorded as low as $-5^{\circ} \mathrm{C}\left(23^{\circ} \mathrm{F}\right)$ during the winter season. The maximum net radiation flux was recorded 6.6 $\mathrm{kJ} / \mathrm{d} / \mathrm{m}^{2}$ in the summer, and it dropped to almost 4.4 $\mathrm{kJ} / \mathrm{d} / \mathrm{m}^{2}$ in the winter as shown in the Fig. 4(b).
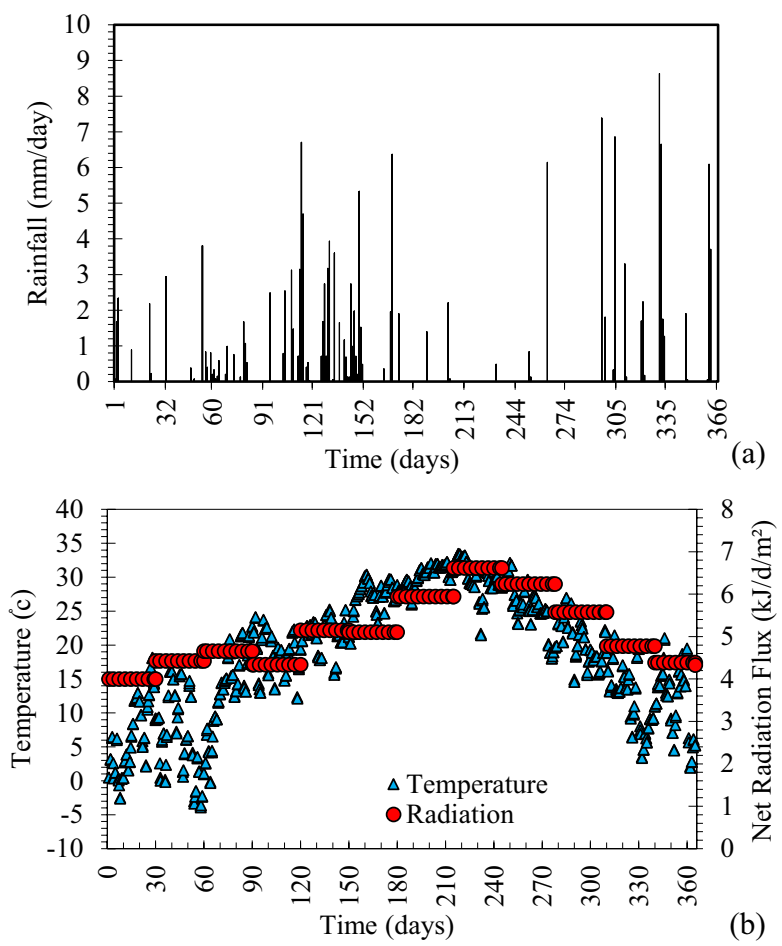

Fig. 4. (a) Daily precipitation, and (b) Average atmospheric temperature and radiation flux

\subsection{Land-Climate Interaction Model}

Seep/W (Geo-studio 2020) simulate water flow under variably saturated conditions by solving the modified form of Richards' equation as shown in Equation (5):

$$
\frac{d \theta}{d \Psi} \frac{d \Psi}{d t}=-\frac{\partial}{\partial z}\left[K_{T} \frac{\partial \Psi}{\partial z}+K_{\Psi}+q_{v T}\right]-S(z, t)
$$

Where $\theta$ is volumetric water content, $t$ is time, $z$ is the vertical coordinate. The $\psi$ is the matric suction, $K_{T}$ is a combined liquid and vapor unsaturated hydraulic conductivity, $K_{\psi}$ is the unsaturated hydraulic conductivity, $q_{v T}$ is water vapor flux, and $S$ is a sink term for extraction of pore water by plant roots. The steadystate evaporation process can be modeled by considering the combined liquid and vapor flow conductivity $\left(K_{T}\right)$. It is known that the pressure head distribution within the dry zone can be modeled after accounting for the vapor flow contribution [30]. The climate variability can be incorporated in the seepage analysis by applying the landclimate interaction (LCI) boundary condition. The LCI boundary condition calculates the net infiltration at the ground surface and the soil strata's root water uptake. The following equation calculates the infiltration through the surface.

$$
q_{l}=\left(q_{P}+q_{M}\right) \cos \alpha+q_{E}+q_{R}
$$

Where $q_{l}$ is water flux due to infiltration, $q_{P}$ is water flux due to rainfall, $q_{M}$ is water flux due to snowmelt, $q_{E}$ is water flux due to evaporation, $q_{R}$ is water flux due to runoff, and $\alpha$ is the slope angle. The potential evapotranspiration is calculated by the Penman-Monteith equation, which incorporated net radiation, ground heat flux, and vegetation properties. The detail of this equation can be found in [31]. On the other hand, the root water uptake rate is determined from the potential transpiration flux $q_{P T}$ by following equation developed by Feddes [32].

$$
q_{\text {root }}=\alpha_{r w} \times \alpha_{r s} \times \pi_{R r o o t} \times q_{P T}
$$

Where $q_{\text {root }}$ is the actual root water availability, $\alpha_{r w}$ and $\alpha_{r s}$ are the reduction factor due to water stress and salinity stresses, $\pi_{\text {root }}$ is the normalized water uptake, and $q_{P T}$ is the potential transpiration flux.

A land-climate interaction type flux boundary condition was applied at the surface to simulate infiltration of precipitation and evaporation from the soil surface. A unit hydraulic gradient or a seepage face boundary was used at the bottom of the domain. Rainwater infiltration depends on soil porosity, as well as on the hydraulic conductivity of the soil. And, evaporation component mainly depends on weather and vegetation conditions as characterized by the LAI and RLD function. The simulation for this study began on January 1, 2015. The initial condition for the transient analysis was defined by the activation of pore-water pressure in the material definition on this date.

The cover was subjected to seasonal wetting and drying cycles. Since there was an impermeable geomembrane layer at the bottom of the subgrade soil, the numerical modeling was performed by integrating an impermeable layer at the bottom of the cover system. The simulated one-dimensional soil profile consists of 915 $\mathrm{mm}$ of compacted clay overlain by $305 \mathrm{~mm}$ of surface layer.

\section{Results and Discussion}

Simulations were conducted with SEEP/W for the period between January 01, 2015 and December 31, 2015. Predictions obtained using the field fit hydraulic properties and plant properties are shown in Fig. 5 in terms of the primary water balance quantities: cumulative precipitation and runoff (Fig. 5a), cumulative ET (Fig. 5b), soil water storage (Fig. 5c), and cumulative percolation (Fig. 5d). The field water balance data are also 
shown in Fig. 5. The prediction of surface runoff pattern in SEEP/W is almost identical to the field measured runoff. The input of precipitation distribution in the model from the field observation appears to be reasonable for the better accuracy of surface runoff. The annual runoff based on the field measurement and numerical simulation was found $943 \mathrm{~mm}$ and $1030 \mathrm{~mm}$, respectively. The precipitation intensity in the field was found as high as $160 \mathrm{~mm} / \mathrm{hr}$. From the field observation, the total quantity of runoff from a given precipitation event was found to be correlated to the rainfall intensity and duration. The surface runoff occurred when the rainfall intensity exceeded the infiltration capacity of the soil. The model predicted runoff is providing better accuracy as well for the field measured hydraulic properties as input. The $\mathrm{K}_{\mathrm{s}}$ is, therefore, plays an important role in the simulation process.

Good agreement exists between the field measured and model-predicted evapotranspiration as shown in Fig. 5 b. However, the model predicted cumulative ET (803 m) was slightly higher than the field measured value (720.8 $\mathrm{mm}$ ). The field measured plant parameters as input in the simulation process reasonably captured the field ET. It is also observed from the soil water storage profile (Fig. 5c) that sufficient water entered the cover and was available for evaporation and transpiration. Relatively accurate prediction of surface runoff allowed water to enter the cover and become available for evaporation and transpiration.

A good agreement also exists between the model predicted and field-measured soil water storage (SWS) as shown in Fig. 5c. The SWS increased during the rainfall period and decreased during the summer. It is also observed from the field results that the fluctuation in the SWS was minimal during the winter period as seen at the end of the monitoring (Fig. 5c). A parallel trend was observed in the model predicted results. The SWS was slightly under-predicted during the winter from model prediction. This might be because of the overprediction of the ET that reduces the SWS in the model results. However, the model reasonably captured the seasonal change of the moisture variation. The good agreement between the measured and predicted SWS data is most likely due to the relatively precise prediction of the surface runoff.

Evaluation of the field measured, and model predicted percolation are shown in Fig. 5d. It is observed from the figure that SEEP/W under predicted the percolation. The model predicted annual percolation was approximately 45 $\mathrm{mm}$, whereas the field measured value was approximately $62 \mathrm{~mm}$. It is also observed from the field percolation data that at the end of the winter of the monitoring period, percolation increased at a higher rate than the model prediction. The underprediction of the percolation and comparatively accurate prediction of the other water balance quantities indicates that differences likely exist between the soil hydraulic properties existing in the field and the laboratory-measured properties when used as input to the models. Though the saturated and unsaturated soil properties from the field measurement were used as the model input, the prediction of percolation was inadequate compared to other water balance components.
So, it indicates the presence of preferential flow paths in the cover, which the model could not define. The author reported the existence of desiccation cracks in the covers during the monitoring period [33].

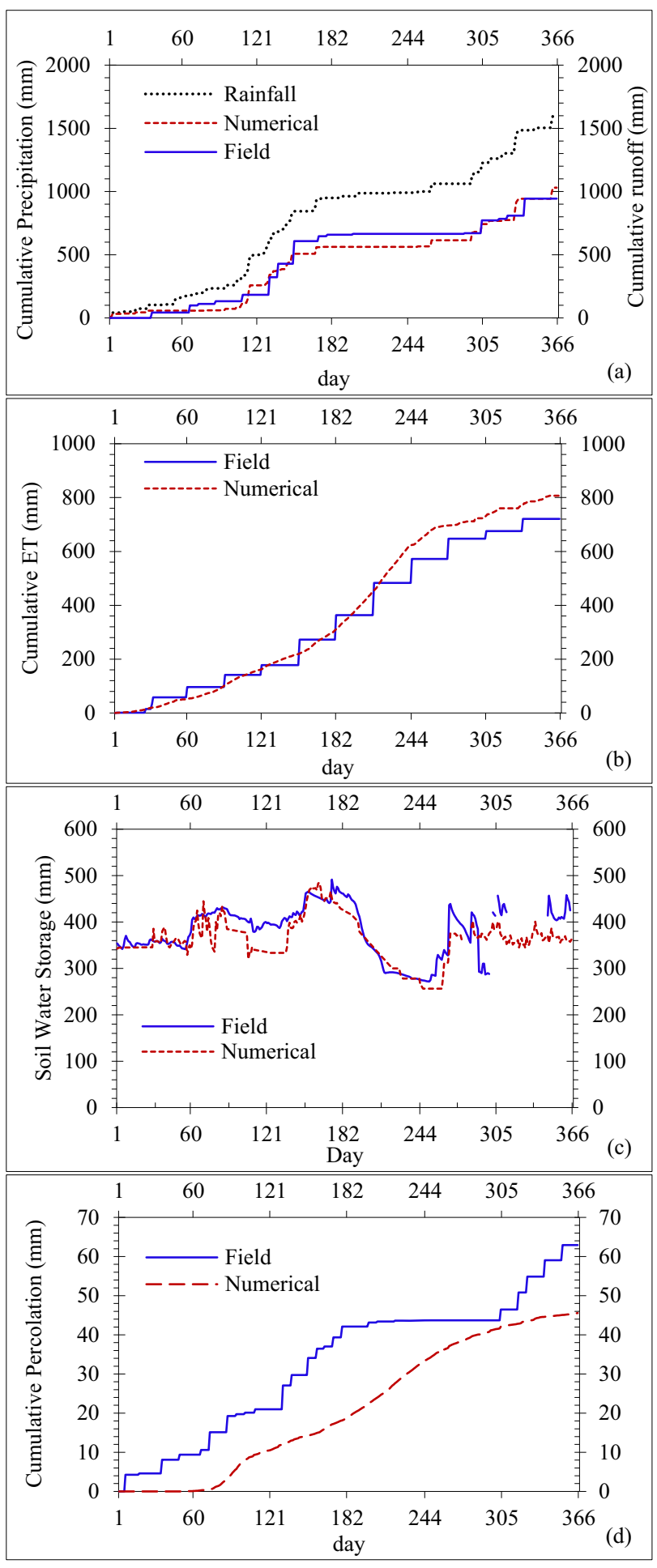

Fig. 5 Water Balance Components (a) Precipitation and runoff, (b) Evapotranspiration, (c) Soil water storage, (d) Percolation

\section{Conclusion}

This paper illustrated the comparison between water balance predictions made with the numerical model SEEP/W and field data of a monolithic ET cover in a 
semi-humid region. On-site climatological data, field measured plant properties, and hydraulic properties were used as input to the models.

SEEP/W projected the surface runoff, ET, and changes in SWS reasonably accurately using the field measured plant and soil properties as input. However, percolation was under-predicted by the model. The on-site precipitation intensity data as input contributed to the better resolution of the runoff prediction. Therefore, application of the precipitation data in the model that closely resembles field conditions is crucial for better accuracy in the prediction. The actual plant parameters used in the model influenced the prediction of evapotranspiration. Though the model predicted cumulative ET was slightly higher than the field value, it closely followed the trend of field evapotranspiration. The SWS was satisfactorily predicted by the model. The increase and decrease in the SWS due to the change in the environmental effect were precisely captured by the model.

The under-prediction of percolation by the model is potentially associated with the presence of preferential flow paths (desiccation cracks) even though the field measured hydraulic properties were used as input. However, the model could portray the field parallel propagation path of percolation.

Based on the preliminary simulation of one-year data, the SEEP/W model reasonably predicted the water balance components. However, further study with rigorous data set from long-term field monitoring is required for the sensitivity of the model prediction for future design.

\section{References}

1. C. Benson, T. Abichou, W. Albright, G. Gee, A. Roesler. (2001). Field Evaluation of Alternative Earthen Final Covers. International Journal of Phytoremediation, 3(1), 105-127.

2. S. Dwyer. (2000). Construction overview of six landfill cover designs. Sandia Rep. SAND2000-2428, Sandia National Laboratories, Albuquerque, NM.

3. J. Zornberg, L. LaFountain, J. Caldwell. (2003). Analysis and design of evapotranspirative cover for hazardous waste landfill. J. Geotech. Geoenviron. Eng., 129(5), 427-438.

4. W. Albright, C. Benson, G. Gee, A. Roesler, T. Abichou, P. Apiwantragoon, B. Lyles, S. Rock. (2004). Field water balance of landfill final covers. Journal of Environ. Qual., 33(6), 2317-2332.

5. J. Stormont \& C. Morris. (1998). Method to Estimate Water Storage Capacity of Capillary Barriers. J. Geotech. Geoenviron. Eng., 124(4), 297-302.

6. M. Khire, C. Benson, P. Bosscher. (2000). Capillary Barriers: Design Variables and Water Balance. J. Geotech. Geoenviron. Eng., 126(8), 695-708.

7. C. Benson, W. Albright, A. Roesler, T. Abichou. (2002). Evaluation of final cover performance: field data from the alternative cover assessment program (ACAP). Proc. Waste Management, 2: 1-15.
8. M. Malusis \& C. Benson. (2006). Lysimeter versus Water-Content Sensors for Performance Monitoring of Alternative Earthen Final Covers. Unsaturated Soils 2006, 741-752.

9. C. Bohnhoff, A. Ogorzalek, C. Benson, C. Shackelford, P. Apiwantragoon. (2009). Field Data and Water-Balance Predictions for a Monolithic Cover in a Semiarid Climate. J. Geotech. Geoenviron. Eng., 135(3), 333-348.

10. W. Albright, C. Benson, W. Waugh. (2010). Water balance covers for waste containment: Principles and practice, ASCE, Reston, VA.

11. K. Barnswell \& D. Dwyer. (2010). Assessing the performance of evapotranspiration covers for municipal solid waste landfills in Northwestern Ohio. Journal of Environmental Engineering, 137(4), 301305.

12. M. Alam \& M. Hossain. (2019). Evaluation of PostConstruction Changes in Soil Hydraulic Properties through Field Instrumentation and In Situ Testing. In Geo-Congress 2019: Geotechnical Materials, Modeling, and Testing, Reston, VA: American Society of Civil Engineers, 722-732.

13. L. Hoyos, M. Alam, M. Hossain, B. Haney. (2019). Monitoring Seasonal Variation of Soil Hydraulic Conductivity of Evapotranspiration (ET) Cover. In Geo-Congress 2019: Geo-Environmental Engineering and Sustainability, Reston, VA: American Society of Civil Engineers, 72-81.

14. C. Benson \& M. Othman. (1993). Hydraulic conductivity of compacted clay frozen and thawed in situ. J. Geotech. Eng., 119(2), 276-294.

15. E. Chamberlain \& A. Gow. (1979). Effect of freezing and thawing on the permeability and structure of soils. Eng. Geol., 13(1-4), 73-92.

16. W. Waugh, C. Benson, W. Albright. (2009). Sustainable covers for uranium mill tailings, USA: Alternative design, performance, and renovation. In Proceedings of 12th International Conference on Environmental Remediation and Radioactive Waste Management, 639-648.

17. B. Albrecht \& C. Benson. (2001). Effect of Desiccation on Compacted Natural Clays. J. Geotech. Geoenviron. Eng., 127(1), 67-75.

18. E. Ayres, J. Heath, M. Possell, H. Black, G. Kerstiens, R. Bardgett. (2004). Tree physiological responses to above-ground herbivory directly modify below-ground processes of soil carbon and nitrogen cycling. Ecology Letters, 7(6), 469-479.

19. W. Albright \& C. Benson. (2002). Alternative cover assessment program, 2002 annual report. Publication No. 41182. Division of Hydrological Sciences, Desert Research Institute, University and Community College System of Nevada, and Univ. of WisconsinMadison.

20. J. Nyhan. (2005). A seven-year water balance study of an evapotranspiration landfill cover varying in 
slope for semiarid regions. Vadose Zone J, 4(3), 466480.

21. B. Scanlon, R. Reedy, K. Keese, S. Dwyer. (2005). Evaluation of evapotranspirative covers for waste containment in arid and semiarid regions in the southwestern USA. Vadose Zone J, 4(1), 55-71.

22. M. Fayer \& T. Jones. (1990). Unsaturated Soil-Water and Heat Flow Model, version 2.0. Pacific Northwest Lab., Richland, Washington.

23. M. Khire, C. Benson, P. Bosscher. (1997). Water Balance Modeling of Earthen Landfill Covers. J. Geotech. Geoenviron. Eng., 123(8), 744-754.

24. A. Roesler \& C. Benson. (2002). Field hydrology and model predictions for final covers in the alternative assessment program. Geo Engineering report no. 0208, University of Wisconsin, Madison, WI.

25. M. Alam. (2017). Evaluation of Plant Root on the Performance of Evapotranspiration Cover Systems. Doctoral Thesis, University of Texas at Arlington, Texas, USA.

26. M. Van Genuchten. (1980). A closed-form equation for predicting the hydraulic conductivity of unsaturated soils. Soil science society of America journal, 44(5), 892-898.

27. D. Fredlund \& A. Xing. (1994). Equations for the soil-water characteristic curve. Canadian geotechnical journal, 31(4), 521-532.

28. M. Fayer. (2000). UNSAT-H version 3.0: Unsaturated soil water and heat flow model - Theory, User Manual and Examples. PNNL-13249, Pacific Northwest National Laboratory, Richland, WA 99352.

29. U.S. Department of Agriculture, Natural Resources Conservation Service (USDA-NRCS). (2003). National Soil Survey characterization data. Soil Survey Laboratory, National Soil Survey Center, Lincoln, Neb.

30. M. Sadeghi, M. Tuller, M. Gohardoust, S. Jones. (2014). Column-scale unsaturated hydraulic conductivity estimates in coarse-textured homogeneous and layered soils derived under steadystate evaporation from a water table. Journal of Hydrology, 519, 1238-1248.

31. G. Allen, L. Pereira, D. Raes, M. Smith. (1998). Crop Evapotranspiration-Guidelines for computing crop water requirements. FAO Irrigation and Drainage Paper 56. FAO, Rome, Italy, 78-86.

32. R. Feddes, H. Hoff, M. Bruen, T. Dawson, P, De Rosnay, P. Dirmeyer, R. Jackson, P. Kabat, A. Kleidon, A. Lilly, A. Pitman. (2001). Modeling root water uptake in hydrological and climate models. Bulletin of the American meteorological society, 82(12), 2797-2810.

33. M. Alam, B. DeVries, N. Rahman, M Hossain (2019). Field Hydrologic Performance of Water Balance Cover in North Texas. In Geo-Congress 2019 (pp. 95-104). Reston, VA: American Society of Civil Engineers. 